특집논문-10-15-6-08

$$
\begin{gathered}
\text { 복호후재전송을 사용하는 양방향 OFDMA 중계 네트워크에서 } \\
\text { 다중사용자를 위한 부반송파 할당 기법 } \\
\text { 신 한 목 }{ }^{\ddagger}, \text { 이 재 홍a) }
\end{gathered}
$$

\title{
Subcarrier Allocation for Multiuser in Two-Way OFDMA Relay Networks using Decode-and-Forward Relaying
}

\author{
Hanmok Shin ${ }^{\text {a) }}$ and Jae Hong Lee ${ }^{a)}$ \\ 요 약
}

양방향 중계 네트워크는 중계기에 중첩 부호화 또는 네트워크 부호화를 적용함으로써 기존의 단방향 중계 네트워크에 비해 향상된 주파수 효율을 제공한다. 한편, OFDMA 네트워크는 사용자에게 부반송파, 파워 등의 자원을 적응적으로 할당하여 네트워크의 성능 향상을 얻을 수 있다. 본 논문에서는 복호후재전송을 사용하는 양방향 OFDMA 중계 네트워크에서 다중사용자를 위한 적응적 부반송 파 할당 알고리즘을 제안한다. 제안된 알고리즘은 각 사용자 쌍의 최소 전송속도를 보장하며 모든 사용자 쌍에 대한 달성 합 전송속도 를 최대화하기 위해 부반송파를 사용자 쌍과 중계기에 적응적으로 할당한다. 모의실험을 통해 제안된 알고리즘이 정적 알고리즘, 그리

디 알고리즘 보다 우수한 성능을 보임을 확인한다.

\begin{abstract}
A two-way relay network provide improved spectral efficiency compared with a conventional one-way relay network by using either superposition coding or network coding. OFDMA network provides imptoved performance by adaptive resource allocation. In this paper, we propose a adaptive subcarrier allocation for a multiuser two-way OFDMA relay network. In the proposed algorithm, subcarriers are allocated to the user-pairs and relays to maximize the achievable sum-rate over all user-pairs while satisfying the minimum rate requirement for each user-pair. Simulation results show that the proposed algorithm provides improved performance compared with the static and greedy algorithms.
\end{abstract}

Keyword : subcarrier allocation, two-way relaying, OFDMA, decode-and-forward.

\section{I. 서 론}

다이버시티(diversity) 기법은 무선 통신 네트워크에서 다

a) 서울대학교 전기 컴퓨터공학부, 뉴미디어통신공동연구소

Department of Electrical Engineering and INMC, Seoul National Univ. \# 교신저자 : 신한목 (hmshin@snu.ac.kr)

※이 논문은 2010 년도 정부(교육과학기술부)의 재원으로 한국연구재단의 지원을 받아 수행된 연구임(No. 2010-0001964).

· 접수일(2010년8월30일),수정일(2010년11월10일),게재확정일(2010년11월11일)
중경로 페이딩(multipath fading)에 의해 발생되는 성능 감 소를 완화시키기 위해 널리 이용된다. 무선 통신 네트워크 에서 다중송수신안테나(MIMO: multiple input multiple output)는 공간 다이버시티(spatial diversity) 이득을 얻을 수 있으며, 따라서 네트워크의 주파수 효율(spectral efficiency)과 안정성(reliability)이 향상된다 ${ }^{[1] 2]}$. 그러나 사용 자의 크기, 파워, 그리고 복잡도 등의 제한 조건 때문에 사 
용자에 다중안테나를 설치하는 것은 비현실적이다. 그 대 안으로 제안된 협력 다이버시티(cooperative diversity) 기법 에서는 하나의 안테나를 가진 사용자들과 중계기들이 서로 자원을 공유하여 가상의 안테나 배열(virtual antenna array) 을 형성하며, 따라서 사용자와 중계기에 다중안테나를 설 치하지 않고도 공간 다이버시티 이득을 얻을 수 있다 ${ }^{[3]-[5]}$.

OFDMA(orthogonal frequency division multiple access) 는 주파수 선택적 페이딩(frequency selective fading)과 심 볼간 간섭(ISI: inter-symbol interference)의 문제를 해결하 기 위한 효과적인 방법 중 하나로 많은 관심을 받고 있다. OFDMA 네트워크에서 총 대역폭은 많은 수의 부반송파로 쪼개어지고, 다중사용자는 서로 다른 부반송파를 이용해 동시에 정보를 송신한다. OFDMA 네트워크는 사용자에게 부반송파, 파워 등의 자원을 적응적으로 할당하여 네트워 크의 성능 향상을 얻을 수 있음이 알려져 있다 ${ }^{[6-[8]}$.

기존의 반이중방식(half duplex) 단방향 중계 네트워크는 하나의 정보를 두 개의 시간 슬롯 동안에 보내므로 추가적인 자원을 필요로 하며 이로 인해 주파수 효율에서 감소가 생기 게 된다. 이러한 주파수 효율의 감소를 없애기 위해 양방향 중계 네트워크가 제안되었다 ${ }^{[9][10]}$. 양방향 중계 네트워크에 서는 중계기에 중첩 부호화(superposition coding) 또는 네트 워크 부호화(network coding)을 적용하여 두 개의 정보를 두 시간 슬롯 동안에 보내므로 단방향 중계 네트워크에 비해 향상된 주파수 효율을 제공한다. 한 개의 사용자 쌍과 한 개 의 중계기가 존재하는 양방향 $\mathrm{OFDM}$ 중계 네트워크에서 적 응적 파워 할당과 부반송파 치환(subcarrier permutation)을 이용하여 합 채널용량(sum-capacity)을 최대화하는 기법이 제안되었으며 ${ }^{[11]}$, 기지국과 다중사용자가 양방향 통신을 하 는 다중사용자 양방향 OFDMA 중계 네트워크에서의 자원 할당 기법 또한 제안되었다 ${ }^{[12]}$. 그러나 다중사용자 쌍과 다 중중계기가 존재하는 양방향 OFDMA 중계 네트워크를 위 한 자원 할당 기법에 대해서는 아직 연구되지 않았다.

본 논문에서는 복호후재전송을 사용하는 양방향 OFDMA 중계 네트워크에서 다중사용자를 위한 적응적 부반송파 할 당 알고리즘을 제안한다. 먼저 모든 사용자 쌍에 대한 달성 합 전송속도를 최대화하기 위한 최적화 문제를 정형화한다. 시스템의 수명을 늘이고 각 사용자의 최소 전송속도를 보장
하기 위해 공정성 제한을 고려한다. 그리고 이로부터 적응적 부반송파 할당 알고리즘을 제안한다. 컴퓨터 모의실험을 통 해 제안된 기법을 기존의 기법과 비교한다. 제안된 기법은 차량 간(V2V: Vehicle-to-Vehicle) 통신 또는 차량과 인프라 간(V2I: Vehicle-to-Infrastructure) 통신에 적용되어 높은 신 뢰성과 효율성을 제공할 수 있을 것으로 기대된다.

본 논문의 구성은 다음과 같다. 2절에서는 시스템 모델을 보인다. 3절에서는 공정성 제한을 고려한 최적화 문제를 정 형화하고, 새로운 적응적 부반송파 할당 알고리즘을 제안 한다. 4절에서는 모의실험을 통해 제안된 기법의 성능을 확 인하며, 5절에서 결론을 맺는다.

\section{II. 시스템 모델}

그림 1 과 같이 $K$ 개의 사용자 쌍과 $M$ 개의 중계기가 존 재하는 다중사용자 양방향 중계 네트워크를 고려한다. 다중 접속 방식으로 $N$ 개의 부반송파를 갖는 OFDMA 방식을 사 용한다. $k$ 번째 사용자 쌍의 두 사용자, $A_{k}$ 와 $B_{k}, k=1, \ldots, K$, 는 한 개 또는 그 이상의 중계기의 도움을 받아 서로의 정보 를 교환한다. 각 사용자 간의 직접 경로는 없다고 가정한다. 또한 각 사용자와 중계기는 한 개의 안테나를 가지고 있으 며, 송신과 수신을 동시에 할 수 없다고 가정한다.

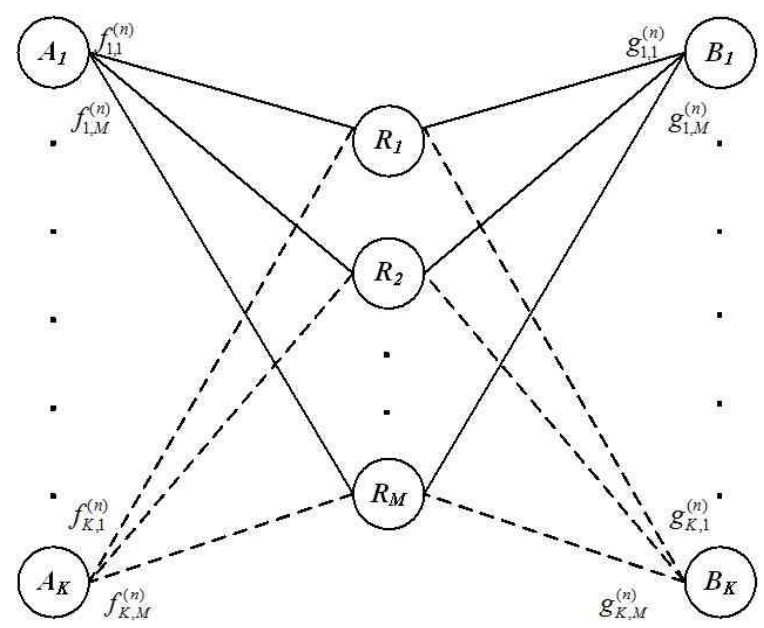

그림 1. 다중사용자 양방향 중계 네트워크의 시스템 모델

Fig. 1. System model for a multiuer two-way relay network 
모든 중계기는 복호후 재전송 중계 기법을 사용한다.

무선통신 채널은 주파수 선택적 레일리 페이딩을 가정한 다. 또한 각 부반송파의 대역폭은 채널의 상관 대역폭보다 훨씬 작으며, 따라서 각 부반송파의 채널은 평면 페이딩 (flat fading)을 갖는다고 가정한다. 사용자 $A_{k}$ 와 중계기 $R_{m}$ 사이의 $n$ 번째 부반송파의 채널을 $f_{k, m}^{(n)}$ 라 하고, 사용 자 $B_{k}$ 와 중계기 $R_{m}$ 사이의 $n$ 번째 부반송파의 채널을 $g_{k, m}^{(n)}$ 라 한다.

양방향 중계에서 두 사용자는 다중접속단계(multiple-access phase)와 방송단계(broadcast phase), 두 단계에 걸쳐서 서로 데이터를 교환한다. 다중접속단계에서 모든 사용자는 자신의 데이터를 동시에 중계기로 전송하며, 각 중계기는 수신한 신호들을 각각 복호한다. 방송단계에서 각 중계기 는 다중접속단계에서 복호한 신호들을 더하여 사용자들에 게 방송한다. 양방향 중계 네트워크에서는, 위 과정에서 각 사용자는 자신이 송신한 신호를 다시 수신하게 되는데 이 를 자기간섭(self-interference)라 한다. 본 논문에서는 자기 간섭을 완벽하게 제거할 수 있다고 가정한다.

$k$ 번째 사용자 쌍이 $n$ 번째 부반송파를 이용하여 $m$ 번째 릴레이의 도움을 받아 통신하는 경우의 순시 전송속도 (instantaneous rate)는 다음과 같다 ${ }^{[9]}$.

$$
r_{k, m}^{(n)}=\min \left(r_{k, m, M A}^{(n)}, r_{k, m, A B}^{(n)}+r_{k, m, B A}^{(n)}\right)
$$

(1)의 각 항목은 다음과 같다.

$$
\begin{gathered}
r_{k, m, M A}^{(n)}=\frac{1}{2} \log _{2}\left(1+\frac{p_{A_{k}}^{(n)}\left|f_{k, m}^{(n)}\right|}{\sigma^{2}}+\frac{p_{B_{k}}^{(n)}\left|g_{k, m}^{(n)}\right|}{\sigma^{2}}\right) \\
r_{k, m, A B}^{(n)}=\frac{1}{2} \min \left\{\log _{2}\left(1+\frac{p_{A_{k}}^{(n)}\left|f_{k, m}^{(n)}\right|}{\sigma^{2}}\right), \log _{2}\left(1+\frac{p_{R_{m}}^{(n)}\left|g_{k, m}^{(n)}\right|}{\sigma^{2}}\right)\right. \\
r_{k, m, B A}^{(n)}=\frac{1}{2} \min \left\{\log _{2}\left(1+\frac{p_{B_{k}}^{(n)}\left|g_{k, m}^{(n)}\right|}{\sigma^{2}}\right), \log _{2}\left(1+\frac{p_{R_{m}}^{(n)}\left|f_{k, m}^{(n)}\right|}{\sigma^{2}}\right)\right.
\end{gathered}
$$

위의 순시 전송속도로부터 $k$ 번째 사용자 쌍의 달성 전송 속도(achievable rate)는 다음과 같이 나타낼 수 있다.

$$
r_{k}=\sum_{m=1}^{M} \sum_{n=1}^{N} \rho_{k, m}^{(n)} r_{k, m}^{(n)}
$$

여기서 $\rho_{k, m}^{(n)}$ 는 부반송파 할당 표시 변수(subcarrier assignment indicator variable)이다. 만약 부반송파 $n$ 이 사용 자 쌍 $\left(A_{k}, B_{k}\right)$ 와 중계기 $R_{m}$ 에 할당되면 $\rho_{k, m}^{(n)}$ 의 값은 1 이 되며, 그렇지 않으면 $\rho_{k, m}^{(n)}$ 의 값은 0 이 된다. 각 부반송파 는 오직 한 사용자 쌍과 한 중계기에만 할당된다고 가정한 다. 즉, $\rho_{k, m}^{(n)}$ 의 값이 1 이면 $k^{\prime} \neq k$ 이고 $m^{\prime} \neq m$ 인 모든 $k^{\prime}, m^{\prime}$ 에 대하여 $\rho_{k^{\prime}, m^{\prime}}^{(n)}$ 의 값은 0 이 된다. 따라서 모든 사용 자 간 그리고 모든 중계기 간에는 간섭이 없다고 가정한다.

그리고 모든 사용자 쌍에 대한 달성 합 전송속도 (achievable sum-rate over all user pairs)는 다음과 같다.

$$
r=\sum_{k=1}^{K} r_{k}
$$

\section{III. 부반송파 할당 알고리즘 제안}

각 사용자의 최소 전송속도 조건을 $r_{\mathrm{m} \text { in }}$ 이라 하며, 각 사 용자와 중계기에서의 최대 송신 파워를 각각 $P_{U}, P_{R}$ 이라 한다. 이러한 조건들로부터 모든 사용자 쌍에 대한 달성 합 전송속도를 최대화하기 위한 최적화 문제를 다음과 같이 정형화할 수 있담]

$$
\max \sum_{k=1}^{K} \sum_{m=1}^{M} \sum_{n=1}^{N} \rho_{k, m}^{(n)} r_{k, m}^{(n)}
$$

제한조건 : $\rho_{k, m}^{(n)} \in\{0,1\}, \forall k, m, n$

$$
\begin{gathered}
\sum_{m=1}^{M} \sum_{1 n=1}^{N} \rho_{k, m}^{(n)}=1, \quad \forall n \\
\sum_{n=1}^{N} p_{A_{k}}^{(n)} \leq P_{U}, \quad \forall k
\end{gathered}
$$

$$
\sum_{n=1}^{N} p_{B_{k}}^{(n)} \leq P_{U}, \quad \forall k
$$




$$
\begin{gathered}
\sum_{n=1}^{N} p_{R_{m}}^{(n)} \leq P_{R}, \quad \forall m \\
\sum_{m=1 n=1}^{M} \sum_{k, m}^{N} \rho_{k, m}^{(n)} r_{k, m}^{(n)} \geq r_{\min }, \quad \forall k \\
p_{A_{k}}^{(n)}, p_{B_{k}}^{(n)}, p_{R_{m}}^{(n)} \geq 0, \quad \forall k, m, n .
\end{gathered}
$$

수식 (7)의 최적화 문제는 이산변수와 연속변수를 함께 포함하고 있는 결합 최적화 문제이다. 이 문제는 높은 복잡 도 때문에 최적의 값을 얻기가 어려움이 알려져 있다. 문제 를 풀 수 있도록 접근하기 위해, 부반송파 할당 표시 변수 $\rho_{k, m}^{(n)}$ 가 $[0,1]$ 안의 값을 가질 수 있다고 조건을 완화한다 ${ }^{[6]}$.

$\lambda_{n}, \zeta_{k}, \mu_{k, n}, \eta_{k}, \nu_{k, n}, \kappa_{m}, \xi_{m, n}, \alpha_{k}$, 그리고 $\gamma_{k, m, n}$ 을 음수가 아닌 라그랑지 곱수라 하면, 완화된 최적화 문제를 위한 라그랑지안은 다음과 같다 ${ }^{[13]}$.

$$
\begin{aligned}
L= & -\sum_{k=1}^{K} \sum_{m=1}^{M} \sum_{n=1}^{N} \rho_{k, m}^{(n)} r_{k, m}^{(n)}+\sum_{n=1}^{N} \lambda_{n}\left(\sum_{k=1}^{K} \sum_{m=1}^{M} \rho_{k, m}^{(n)}-1\right) \\
& +\sum_{k=1}^{K} \zeta_{k}\left(\sum_{n=1}^{N} p_{A_{k}}^{(n)}-P_{U}\right)-\sum_{k=1}^{K} \sum_{n=1}^{N} \mu_{k, n} p_{A_{k}}^{(n)} \\
& +\sum_{k=1}^{K} \eta_{k}\left(\sum_{n=1}^{N} p_{B_{k}}^{(n)}-P_{U}\right)-\sum_{k=1}^{K} \sum_{n=1}^{N} \nu_{k, n} p_{B_{k}}^{(n)} \\
& +\sum_{m=1}^{M} \kappa_{m}\left(\sum_{n=1}^{N} p_{R_{m}}^{(n)}-P_{R}\right)-\sum_{m=1}^{M} \sum_{n=1}^{N} \nu_{k, n} p_{R_{m}}^{(n)} \\
& +\sum_{k=1}^{K} \alpha_{k}\left(r_{\min }-\sum_{m=1}^{M} \sum_{n=1}^{N} \rho_{k, m}^{(n)} r_{k, m}^{(n)}\right)-\sum_{k=1}^{K} \sum_{m=1}^{M} \sum_{n=1}^{N} \gamma_{k, m, n} \rho_{k, r}^{(n}
\end{aligned}
$$

수식 (15)를 $\rho_{k, m}^{(n)}$ 에 대해 미분한 후, 다음과 같은 최적의 값을 얻기 위한 Karush-Kuhn-Tucker (KKT) 조건들을 얻 을 수 있다 ${ }^{[13]}$.

$$
\begin{gathered}
\frac{\partial L}{\partial \rho_{k, m}^{(n)}}=\lambda_{n}-\left(1+\alpha_{k}\right) r_{k, m}^{(n)}-\gamma_{k, m, n}=0, \quad \forall k, m, n \\
\lambda_{n}\left(\sum_{k=1}^{K} \sum_{m=1}^{M} \rho_{k, m}^{(n)}-1\right)=0, \quad \forall n \\
\zeta_{k}\left(\sum_{n=1}^{N} p_{A_{k}}^{(n)}-P_{U}\right)=\eta_{k}\left(\sum_{n=1}^{N} p_{B_{k}}^{(n)}-P_{U}\right)=0, \quad \forall k
\end{gathered}
$$

$$
\begin{gathered}
\kappa_{m}\left(\sum_{n=1}^{N} p_{R_{m}}^{(n)}-P_{R}\right)=0, \forall m \\
\mu_{k, n} p_{A_{k}}^{(n)}=\nu_{k, n} p_{B_{k}}^{(n)}=\xi_{m, n} p_{R_{m}}^{(n)}=0, \quad \forall k, m, n \\
\alpha_{k}\left(r_{\min }-\sum_{m=1 n=1}^{M} \sum_{k, m}^{N} \rho_{k, m}^{(n)} r_{k, n}^{(n)}\right)=0, \quad \forall k \\
\gamma_{k, m, n} \rho_{k, m}^{(n)}=0, \quad \forall k, m, n
\end{gathered}
$$

수식 (16)은 다음과 같이 다시 쓸 수 있다.

$$
\gamma_{k, m, n}=\lambda_{n}-\left(1+\alpha_{k}\right) r_{k, m}^{(n)}
$$

$\gamma_{k, m, n}$ 는 음수가 아니기 때문에 (23)의 우변의 식 역시 음수가 아니다. 따라서 $\lambda_{n}$ 는 다음과 같다.

$$
\lambda_{n} \geq\left(1+\alpha_{k}\right) r_{k, m}^{(n)}
$$

수식 (23)을 (22)에 대입하면 다음을 얻을 수 있다.

$$
\left(\lambda_{n}-\left(1+\alpha_{k}\right) r_{k, m}^{(n)}\right) \rho_{k, m}^{(n)}=0
$$

만약 $\rho_{k, m}^{(n)}$ 가 양수 값을 가지면, 부반송파 $n$ 은 $k$ 번째 사 용자 쌍과 $m$ 번째 중계기에 할당되고, 반대로 만약 부반송 파 $n$ 이 $k$ 번째 사용자 쌍과 $m$ 번째 중계기에 할당되면 $\rho_{k, m}^{(n)}$ 가 양수 값을 가진다. $\rho_{k, m}^{(n)}$ 에 대한 상보 여유 조건 (complementary slackness condition)에 의해, 만약 $\rho_{k, m}^{(n)}$ 가 양수 값을 가지면 $\lambda_{n}-\left(1+\alpha_{k}\right)$ 는 0이 되고 수식 (24)의 등호가 성립한다. 그러므로 부반송파 $n$ 은 $\left(1+\alpha_{k}\right) r_{k, m}^{(n)}$ 을 최대화하는 사용자 쌍과 중계기에 할당되어야 한다. 이것 으로부터, 각 사용자 쌍의 최소 전송속도를 보장하며 모든 사용자 쌍에 대한 달성 합 전송속도를 최대화하기 위해, 부 반송파 $n$ 은 다음의 $k^{*}$ 번째 사용자 쌍과 $m^{*}$ 번째 중계기에 할당되어야 한다.

$$
\left(k^{*}, m^{*}\right)=\arg \max \left(1+\alpha_{k}\right) r_{k, m}^{(n)} .
$$


수식 (26)을 통해 부반송파 $n$ 이 할당될 $k^{*}$ 번째 사용자 쌍과 $m^{*}$ 번째 중계기를 찾기 위해서는 $\alpha_{k}$ 의 정확한 값을 알아야 하며, 이것은 반복 탐색 알고리즘을 통해 구할 수 있다. 그러나 $\alpha_{k}$ 을 위한 반복 탐색 알고리즘은 추가적인 복 잡도 상승을 야기한다. 이러한 추가적인 복잡도 상승을 막 기 위해 다음과 같은 부반송파 할당 알고리즘을 제안한다.

1) $U=\{1,2, \ldots, K\}, R=\{1,2, \ldots, M\}, S=\{1,2, \ldots, N\}$, 그리 고 모든 $k, m, n$ 에 대해 $\rho_{k, m}^{(n)}=0$ 으로 초기화한다. 여 기에서 $U, R$, 그리고 $S$ 는 각각 사용자 쌍, 중계기, 그리고 부반송파의 집합을 나타낸다.

2) $\left(m^{*}, n^{*}\right)=\arg \max r_{k, m}^{(n)}$ 을 통해 부반송파와 중계기를 선택해 각 사용자 쌍에 할당한다. 각 사용자 쌍에 대해 선택된 중계기와 부반송파로부터 $\rho_{k, m}^{\left(n^{*}\right)}=1$ 을 할당하 며, 부반송파 집합에서 선택된 부반송파 $n^{*}$ 를 제거한 다. 그리고 각 사용자 쌍에 대한 순시 전송속도를 갱신 한다.

3) 각 사용자 쌍에 대한 순시 전송속도를 비교해 가장 순 시 전송속도가 작은 사용자 쌍, $k^{*}$,를 선택한다. 만약 선택된 사용자 쌍 $k^{*}$ 에 대한 순시 전송속도가 최소 전 송속도 조건을 만족시키지 못한 경우, $\left(m^{*}, n^{*}\right)=$ $\arg \max r_{k, m}^{(n)}$ 을 통해 부반송파와 중계기를 선택해 각 사용자 쌍에 할당한다. 선택된 사용자 쌍, 중계기, 그 리고 부반송파로부터 $\rho_{k, m}^{\left(n^{*}\right)}=1$ 을 할당하며, 부반송파 집합에서 선택된 부반송파 $n^{*}$ 를 제거한다. 그리고 각 사용자 쌍에 대한 순시 전송속도를 갱신한다.

모든 사용자 쌍이 최소 전송속도 조건을 만족시킨 경 우, 남은 부반송파 중 하나, $n^{*}$,를 임의로 선택하고, $\left(k^{*}, m^{*}\right)=\operatorname{argmax} r_{k, m}^{\left(n^{*}\right)}$ 을 통해 사용자 쌍과 중계기를 선택해 부반송파 $n^{*}$ 를 할당한다. 선택된 사용자 쌍, 중 계기, 그리고 부반송파로부터 $\rho_{k, m^{*}}^{\left(n^{*}\right)}=1$ 을 할당하며, 부 반송파 집합에서 선택된 부반송파 $n^{*}$ 를 제거한다. 그 리고 각 사용자 쌍에 대한 순시 전송속도를 갱신한다. 모든 부반송파가 사용자 쌍과 중계기에 할당될 때까지 이 과정을 반복한다.
4) 부반송파를 할당하는 과정에서 특정 사용자 쌍 또는 중계기의 송신 파워가 최대 송신 파워에 도달하게 되 면 사용자 쌍 또는 중계기를 사용자 쌍의 집합 또는 중계기의 집합에서 제거하고 더 이상 부반송파를 할당 하지 않는다.

제안된 알고리즘을 주파수 효율(spectral efficiency)과 불 능 확률(outage probability) 측면에서 정적 알고리즘, 그리 디 알고리즘과 비교한다. 본 논문에서 불능 확률은 각 사용 자 쌍이 최소 전송속도 조건인 $r_{\mathrm{min}}$ 을 달성하지 못 할 확률 로 정의한다. 정적 알고리즘에서 각 부반송파는 채널 상태 를 고려하지 않고 미리 정해진 사용자 쌍과 중계기에 할당 되며 ${ }^{[6]}$, 그 과정은 다음과 같다.

1) $U=\{1,2, \ldots, K\}, R=\{1,2, \ldots, M\}, S=\{1,2, \ldots, N\}$, 그리 고 모든 $k, m, n$ 에 대해 $\rho_{k, m}^{(n)}=0$ 으로 초기화한다. 여 기에서 $U, R$, 그리고 $S$ 는 각각 사용자 쌍, 중계기, 그리고 부반송파의 집합을 나타낸다.

2) 임의의 부반송파 $n^{*}$ 은 $k^{*}=n^{*} \bmod K, m^{*}=n^{*} \bmod M$ 을 통해 선택된 사용자 쌍과 중계기에 할당된다. 부반 송파 $n^{*}$ 과 선택된 사용자 쌍과 중계기에 대한 부반송 파 할당 표시 변수 $\rho_{k^{*}, m^{*}}^{\left(n^{*}\right)}=1$ 을 할당하며, 부반송파 집 합에서 부반송파 $n^{*}$ 를 제거한다.

모든 부반송파가 사용자 쌍과 중계기에 할당될 때까지 이 과정을 반복한다.

그리디 알고리즘에서 각 부반송파는 순시 전송속도를 최 대화하는 사용자 쌍과 중계기에 할당되며 ${ }^{[8]}$, 그 과정은 다 음과 같다.

1) $U=\{1,2, \ldots, K\}, R=\{1,2, \ldots, M\}, S=\{1,2, \ldots, N\}$, 그리 고 모든 $k, m, n$ 에 대해 $\rho_{k, m}^{(n)}=0$ 으로 초기화한다. 여기에서 $U, R$, 그리고 $S$ 는 각각 사용자 쌍, 중계기, 그리고 부반송파의 집합을 나타낸다.

2) 임의의 부반송파 $n^{*}$ 은 $\left(k^{*}, m^{*}\right)=\arg \max r_{k, m}^{\left(n^{*}\right)}$ 을 통해 선택된 사용자 쌍과 중계기에 할당된다. 부반송파 $n^{*}$ 
과 선택된 사용자 쌍과 중계기에 대한 부반송파 할당 표시 변수 $\rho_{k^{*}, m^{*}}^{\left(n^{*}\right)}=1$ 을 할당하며, 부반송파 집합에서 부반송파 $n^{*}$ 를 제거한다.

모든 부반송파가 사용자 쌍과 중계기에 할당될 때까지 이 과정을 반복한다.

3) 부반송파를 할당하는 과정에서 특정 사용자 쌍 또는 중계기의 송신 파워가 최대 송신 파워에 도달하게 되 면 사용자 쌍 또는 중계기를 사용자 쌍의 집합 또는 중계기의 집합에서 제거하고 더 이상 부반송파를 할당 하지 않는다.

\section{IV. 모의실험 결과}

본 모의실험에서는 제안된 부반송파 할당 기법의 성능을 주파수 효율과 불능확률을 통하여 알아본다. $200 m \times 200 m$ 의 2 차원 공간에 총 8 쌍의 사용자 쌍이 균등하게 분포하고, 총 3 개의 중계기가 2 차원 공간의 중간에 세로로 일정한 거 리만큼 떨어져서 고정되어 있다고 가정한다. 한 사용자 쌍 의 두 사용자는 각각 중계기의 오른쪽 영역과 왼쪽 영역에 균등하게 분포한다고 가정한다. 총 128 개의 부반송파가 존 재하며, 각 사용자의 최소 전송속도 조건은 $2.5 \mathrm{Mbps}$ 라고

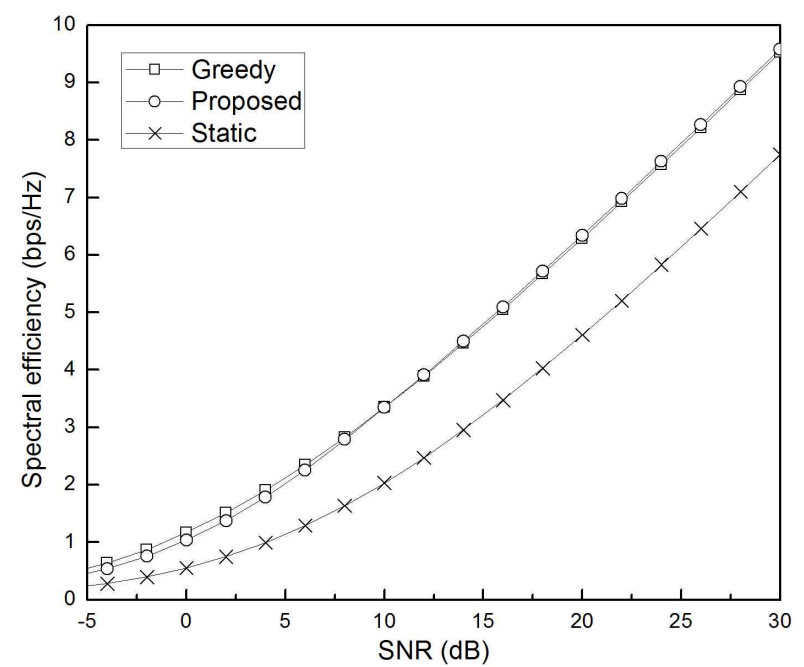

그림 2. 제안된 알고리즘의 주파수 효율

Fig. 2. Spectral efficiency of the proposed algorithm
가정한다. 또한 모든 사용자와 중계기는 동일한 최대 송신 파워를 가진다고 가정한다.

그림 2 는 신호대잡음비에 따른 제안된 알고리즘의 주파 수 효율을 보여준다. 그림을 통해 제안된 알고리즘이 그리 디 알고리즘과 거의 같은 주파수 효율을 얻으며, 정적 알고 리즘보다 훨씬 높은 주파수 효율을 얻음을 알 수 있다. 15 $\mathrm{dB}$ 의 신호대잡음비에서, 제안된 알고리즘은 정적 알고리 즘에 비해 약 $1.5 \mathrm{bps} / \mathrm{Hz}$ 만큼 높은 주파수 효율을 얻으며, 이것은 제안된 알고리즘이 정적 알고리즘에 비해 $50 \%$ 더 향상된 주파수 효율을 얻는 것임을 알 수 있다.

그림 3 은 신호대잡음비에 따른 제안된 알고리즘의 불능 확률을 보여준다. 그림을 통해 제안된 알고리즘이 정적 알고 리즘과 그리디 알고리즘, 두 알고리즘 모두보다 훨씬 낮은 불능 확률을 얻음을 알 수 있다. $10^{-3}$ 의 불능 확률에서 제안 된 기법은 정적 알고리즘보다 약 $8 \mathrm{~dB}$, 그리디 알고리즘보 다 약 $14 \mathrm{~dB}$ 의 신호대잡음비 이득을 얻음을 알 수 있다.

제안된 알고리즘과 그리디 알고리즘은 채널 상태를 고려 하여 부반송파를 할당하므로 채널 상태를 고려하지 않고 부반송파를 할당하는 정적 알고리즘보다 높은 주파수 효율 을 얻는다. 또한 제안된 알고리즘은 각 사용자 쌍의 최소 전송속도 조건을 고려하여 부반송파를 할당하므로 이것을 고려하지 않는 정적 알고리즘과 그리디 알고리즘보다 훨씬

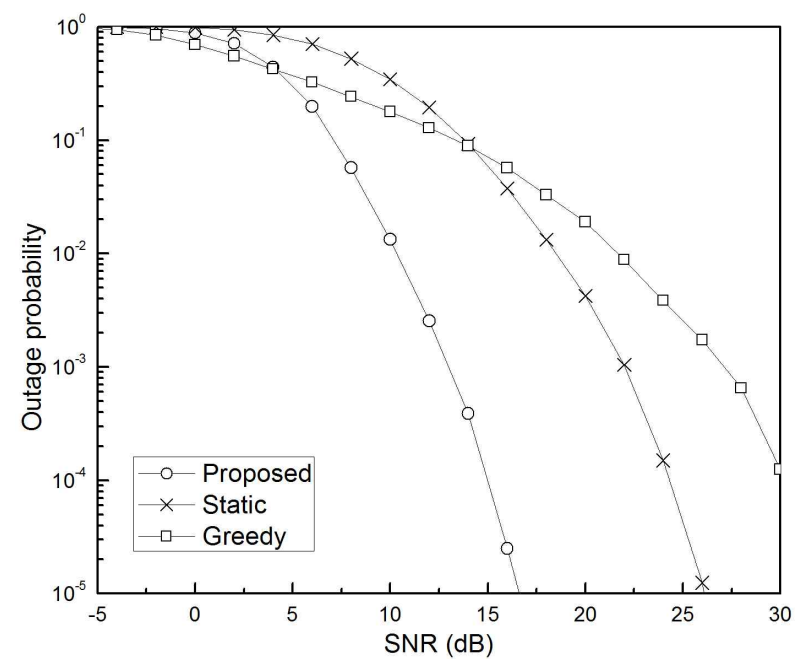

그림 3. 제안된 알고리즘의 불능 확률

Fig. 3. Outage probability of the proposed algorithm 
낮은 불능 확률을 얻는다. 그리디 알고리즘은 채널상태가 좋은 사용자 쌍에 먼저 부반송파를 할당하기 때문에 채널 상태가 좋은 사용자 쌍과 채널 상태가 좋지 않은 사용자 쌍 간에 달성 전송속도에 큰 차이가 생기며, 이로 인해 높은 불능 확률을 얻는다.

\section{V. 결 론}

본 논문에서는 복호후재전송을 사용하는 양방향 OFDMA 중계 네트워크에서 다중사용자를 위한 적응적 부반송파 할 당 알고리듬을 제안하였다. 제안된 알고리즘에서, 최소 전 송속도를 만족시키지 못한 사용자 쌍이 있을 경우 부반송 파는 가장 낮은 달성 전송속도를 가지는 사용자 쌍이 최소 전송속도 조건을 만족시킬 수 있도록 부반송파를 할당한다. 모든 사용자 쌍이 최소 전송속도 조건을 만족시키면 남은 부반송파는 전송속도 향상이 가장 큰 사용자 쌍에 할당된 다. 모의실험을 통해 제안된 알고리즘이 정적 알고리즘보 다 더 높은 주파수 효율을 얻으며, 정적 알고리즘과 그리디 알고리즘, 두 알고리즘 모두 보다 훨씬 낮은 불능확률을 얻 음을 확인하였다.

\section{참 고 문 헌}

[1] V. Tarokh, N. Seshadri, and A. R. Calderbank, "Space-time codes for high-data-rate wireless communication: Performance criterion and code construction," IEEE Trans. Inform. Theory, vol. 44, no. 2, pp.
744-765, Mar. 1998.

[2] A. Goldsmith, S. A. Jafar, N. Jindal, and S. Vishwanath, "Capacity limits of MIMO channels," IEEE J. Sel. Areas Commun., vol. 21, no. 5, pp. 684-702, June 2003.

[3] A. Sendonaris, E. Erkip, and B. Aazhang, "User cooperation diversity-Part I : System description," IEEE Trans. Commun., vol. 51, no. 11, pp. 1927-1938, Nov. 2003.

[4] J. N. Laneman and G. W. Wornell, "Distributed space-time-coded protocols for exploiting cooperative diversity in wireless networks," IEEE Trans. Inform., Theory, vol. 49, no. 10, pp. 2415-2425, Oct. 2003.

[5] J. N. Laneman, D. N. C. Tse, and G. W. Wornell, "Cooperative diversity in wireless networks: Efficient protocols and outage behavior," IEEE Trans. Inform. Theory, vol. 50, no. 12, pp. 3062-3080, Dec. 2004.

[6] C. Y. Wong, R. S. Cheng, K. B. Letaief, and R. D. Murch, "Multiuser OFDMA with adaptive subcarrier, bit, and power allocation," IEEE J. Sel. Areas Commun., vol. 17, no. 10, pp. 1747-1758, Oct. 1999.

[7] W. Rhee and J. M. Cioffi, "Increase in capacity of multiuser OFDM system using dynamic subchannel allocation," in Proc. IEEE VTC2000-Spring, Tokyo, Japan, May 2000, pp. 1085-1089.

[8] G. Li and H. Liu, "Resource allocation for OFDMA relay network with fairness constraints," IEEE J. Sel. Areas Commun., vol. 24, no. 11, pp. 2061-2069, Nov. 2006.

[9] B. Rankov and A. Wittneben, "Spectral efficient protocols for half-duplex fading relay channels," IEEE J. Sel. Areas Commun., vol. 25, no. 2, pp. 379-389, Feb. 2007.

[10] S, J. Kim, P. Mitran, and V. Tarokh, "Performance bounds for bidirectional coded cooperation protocols," IEEE Trans. Inform. Theory, vo. 54, no. 11, pp. 5235-5241, Nov. 2008.

[11] C. K. Ho, R. Zhang, and Y. C. Liang, "Two-way relaying over OFDM: Optimized tone permutation and power allocation," in Proc. IEEE ICC 2008, Beijing, China, May 2008, pp. 3908-3912.

[12] K. Jitvanichphaibool, R. Zhang, and Y. C. Liang, "Optimal resource allocation for two-way relay-assisted OFDMA," IEEE Trans. Veh. Tech., vol. 58, no. 7, pp. 3311-3321, Sep. 2009.

[13] S. Boyd and L. Vandenberghe, Convex Optimization, Cambridge University Press, 2004.

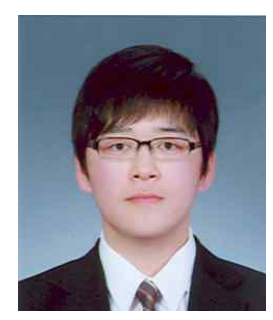

신 한 목

- 2008년 : 경북대학교 전자전기컴퓨터학부 학사

- 2010년 : 서울대학교 전기 컴퓨터공학부 석사

- 2010년 현재 : 서울대학교 전기.컴퓨터공학부 박사과정

- 주관심분야 : MIMO, 협력 다이버시티, 양방향 통신 
저 자 소 개

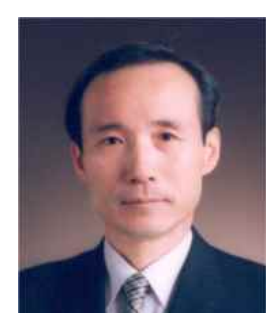

\section{이 재 홍}

- 1976년 : 서울대학교 전자공학과 학사

- 1978년 : 서울대학교 전자공학과 석사

- 1986년 : University of Michigan, Ann Arbor, 전기및컴퓨터공학과 박사

- 1987년 현재 : 서울대학교 전기공학부 교수

- 주관심분야 : 디지털통신, 부호이론, MIMO, OFDM 